Eur J Plast Surg (1997) 20:98-100

\title{
Leiomyosarcoma in a smallpox vaccination scar: case report and review of literature
}

\author{
P. Sendi, S. Krupp \\ Service de Chirurgie Plastique et Reconstructive CHUV Lausanne, Switzerland
}

\begin{abstract}
The development of sarcomas in smallpox vaccination scars is very rare. Including this case, only five have been reported. This is the first report of a leiomyosarcoma arising in a smallpox vaccination scar.
\end{abstract}

Key words: Smallpox vaccination scar - Leiomyosarcoma

In 1882, Marjolin described a squamous cell carcinoma developing in a chronic leg ulcer [1]. "Marjolin's ulcer" describes malignancy in scars [2], venous stasis ulcers, chronic osteomyelitis and chronic fistula and sinuses [3], irradiation dermatitis [4], chronic traumatic wounds [5], and pressure sores [6].

Cancers arising in scars of smallpox vaccinations are uncommon, the first being reported by Auger in 1943 [7]. These are usually of epithelial origin.

In 1993, a patient presented with a leiomyosarcoma in a recurrent hypertrophic smallpox vaccination scar; it infiltrated the underlying subcutis and musculature [8]. This is the first report of a leiomyosarcoma arising in a smallpox vaccination scar.

\section{Case report}

A 33-year-old female was vaccinated against smallpox on her left deltoid area. Five years later in 1976, a painful nodule $1.5 \mathrm{~cm}$ in diameter developed in the scar. The clinical diagnosis was a hypertrophic scar. It was excised but six years later it recurred and was again excised (1982). A second recurrence was excised in 1987. Histology confirmed the clinical diagnosis of scar hypertrophy.

Four months after this a painful nodule appeared. Six years later 1993, because of patient delay, a biopsy revealed a leiomyosarcoma. MRI and CT scans (Figs. 5, 6) determined the extent of the tumor and the patient was referred to us.

Correspondence to: S. Krupp, Avenue des Bergières 2, CH-1004 Lausanne, Switzerland
There was a $6 \mathrm{~cm}$ in diameter painful mass (Fig. 1) with a 1 $\mathrm{cm}$ nodule in the oblique scar of her left shoulder. The tumor was widely excised with the superficial portion of the underlying deltoid, the defect being $10.5 \mathrm{~cm}$ in diameter (Fig. 2). A split thickness skin graft was applied.

A biopsy of a scar-like structure in the skin transplant revealed another recurrence in October 1995. Resection of the deltoid muscle and musculocutaneous reconstruction, supplemented by pre- and postoperative radiotherapy was proposed but rejected by the patient.

\section{Investigations}

- Preoparative CT scans showed a lobular mass on the left deltoid area measuring $5 \mathrm{~cm}$ in the anteroposterior and $4 \mathrm{~cm}$ in the laterolateral scan (Fig. 5). It was located in the subcutaneous tissue, infiltrating the cutis with elevation of the overlying scar and adjacent skin. No local and regional adenopathy was present.

- Preoperative MRI confirmed the CT scan findings (Fig. 6). The superficial muscle fibers of the deltoid were infiltrated.

- Histology showed proliferated spindle-shaped cells with abundant eosinophilic, fibrillar cytoplasm. Polymorphism was rare. Mitotic rate was $15-20$ per $10 \mathrm{HPF}(\times 400)$ (Fig. 7 ). The leiomyosarcoma was mainly located in the subcutis. It infiltrated the dermis superficially and deeply spot-like in the deltoid muscle (Fig. 8). Histology of the overlying dermis showed characteristics of scar hypertrophy (preceding excisions and biopsies). Diagnosis grade II sarcoma.

- Immunohistochemistry confirmed the presence of muscle specific actin and desmin, but absence of cytokeratin and vimentin.

\section{Discussion}

Malignant tumors arising in smallpox vaccination scars are rare. The first was reported in 1943 [7], and 70 cases, including our one, have been described [8]. Of these, 48 were male and 22 female, $58 \%$ after primary vaccination, $25 \%$ after revaccination, and $17 \%$ unknown. The mean age of patients was 53 years, the youngest patient being 15 , the oldest 81 . The mean latent period (interval between vaccination and onset of the lesion or consulting a physician) was 25 year. Three patients were Black, the majority were Causacians. Risk factors were long- 

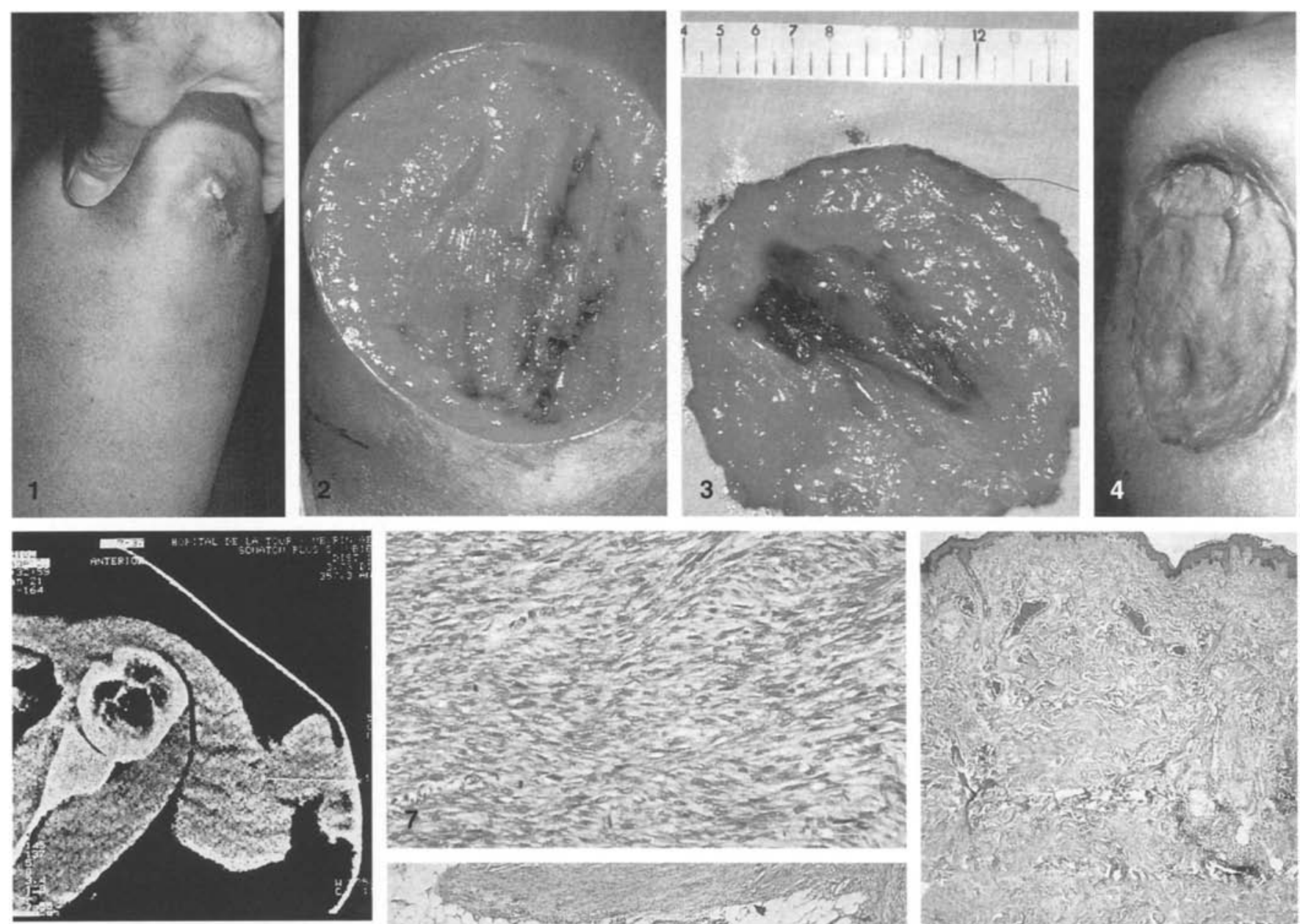

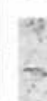

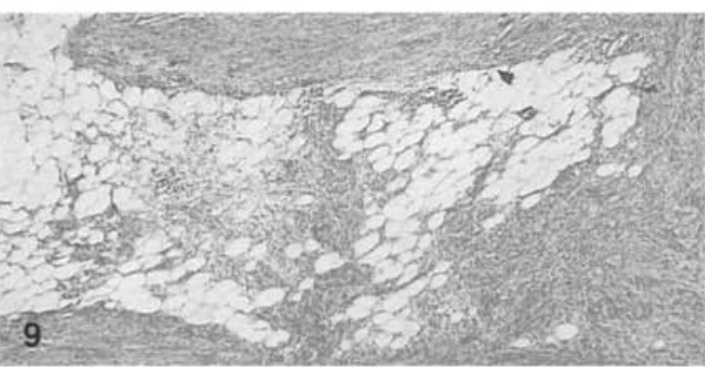

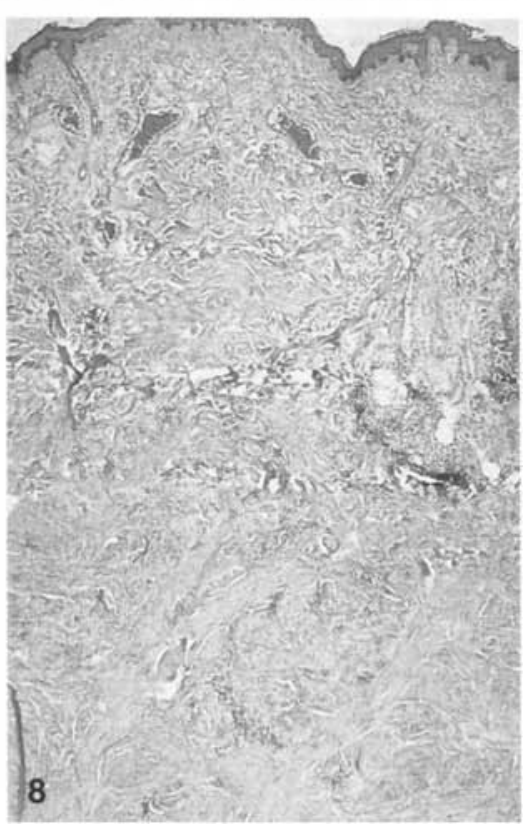

Fig. 1. Preoperative condition shows the leiomyosarcoma in a recurrent hypertrophic smallpox vaccination scar. A nodule is visible at one end of a $3 \mathrm{~cm}$ long scar

Fig. 2. Intraoperative view after wide local excision of the tumour. The cutis, subcutis and superficial part of the deltoid muscle have been removed

Fig. 3. The undersurface of the excised specimen containing the tumoral mass is shown in this figure

Fig. 4. Postoperative condition after 4 months. The wound had been covered with thin split thickness skin graft. The tissue defect has still not been reconstructed for oncologic reasons

Fig. 5. CT-scan at the level of the upper chest shows the tumour infiltrating the subcutaneous fat and the superficial part of the del-

term physical irritation such as sun exposure or chronic scarring, the treatment of choice was local excision [8].

Fifty-seven percent of malignancies in smallpox vaccination scars were basal cell carcinomas. The male to female ratio was $3: 1$. The mean age of patients was 54 years. The mean latent period was 24 years [8]. toid muscle. The tumoral mass presents the same density as the adjacent muscles

Fig. 6. This MRI shows the location of the tumour in the subcutaneous fat overlying the deltoid muscle

Fig. 7. Mitoses of the superficial leiomyosarcoma are shown in this figure. The tumour consists of fascicles intersecting at various angles $(\mathrm{HE}, \times 30)$

Fig. 8. This figure shows the leiomyosarcoma invading the dermis (HE, $\times 10)$

Fig. 9. This figure shows the leiomyosarcoma infiltrating the subcutaneous fat $(\mathrm{HE}, \times 10)$

Twenty-two percent of all reported malignancies in smallpox vaccination scars were malignant melanomas. The male to female ratio was $3: 2$. The mean age of patients was 49 years, $50 \%$ arising between 39 and 58 years. The mean latent period was 22 years [8].

Fourteen percent of all reported malignancies in smallpox vaccination scars were squamous cell carcino- 
mas. The male to female ratio was $2 ; 1$. The mean age of patients was 55 years. The mean latent period was 19 years [8].

Seven percent of all reported malignancies in smallpox vaccination scars were sarcomas. This represented five cases, one fibrosarcoma, two dermatofibrosarcomas protuberans, one malignant fibrohistiocytoma, and this leiomyosarcoma.

Acknowledgement. We thank Drs. L. Guillon, G. Zimmer and E. Saraga of the Institute of Pathology of the University of Lausanne for the histologic examination of the specimen and Dr. H. Hauser, Department of Radiology of the Permanence de l'Hôpital de la Tour, Meyrin, Geneva, for the radiologic imaging.

\section{References}

1. Marjolin JN (1828) Dictionnaire de médecine. Paris, vol 21:46

2. Treves T, Pack GT (1930) The development of cancer in burn scars. Surg Gynecol Obstet 51:749-782

3. Cruickshank AH, McConnell EM, Miller DG (1963) Malignancy in scars, chronic ulcers and sinuses. J Clin Pathol 16:573-580

4. Scharnagl E, Smola MG, Hellbom BA, Pierer G, Hoflehner H (1991) Narbenkarzinom: Beobachtungen und Ergebnisse in 23 Fällen. Langenbecks Arch Chir 376:341-345

5. Look P, Kleinau W, Henze E. Das Fistelkarzinom auf dem Boden der chronischen Osteomyelitis. Zentralbl Chir 102: $998-1005$

6. Mustoe T, Upton J, Marcellino V, Tun CJ, Rossier AB, Hachend JH (1986) Carcinoma in chronic pressure sores. A fulminant disease process. Plast Reconstr Surg 77:116-121

7. Auger C (1943) Cancer sur tatouage et sur cicatrice de vaccination antivariolique. Laval Med 18:300-307

8. Sendi P (1995) Case report of a cutaneous and subcutaneous leiomyosarcoma developing in a recurrent hypertrophic smallpox vaccination scar. Thesis, Faculté Méd, University of Lausanne 